\title{
O BELO ENQUANTO ESPLENDOR DO UM NO TRATADO I, 6 DE PLOTINO
}

\author{
THE BEAUTY AS A SPLENDOR OF THE ONE IN THE TREATY I, 6 OF PLOTINE
}

Vinícius José Henrique da Costa Leonardi*

\begin{abstract}
RESUMO
A partir do tratado Sobre o Belo (I, 6), de Plotino, é discutida no presente artigo a afinidade entre as vias estética e intelectiva como modo de acesso à união com o Um. Para tanto, propomos que o Belo seja entendido como um esplendor do Um, ou seja, como o que se manifesta concomitante e dependente do Um, atraindo para este o olhar daquele que empreende a ascensão filosófica. Assim, procuramos demonstrar que o Belo se fundamenta na intelecção da unidade, e que a ascensão ao Um é tanto estética quanto intelectiva.
\end{abstract}

PALAVRAS-CHAVE: Estética. Alma. Experiência mística. Ascensão. Plotino.

\section{ABSTRACT}

From the treaty On Beauty (I, 6), by Plotinus, the affinity between the aesthetic and intellectual paths as a way of accessing the union with the One is discussed in this article. For that, we propose that the Beauty be understood as a splendor of the One, that is to say, as that one who manifests concomitant and dependent on the One, attracting to the latter the look of one who undertakes the philosophical ascension. Thus, we seek to demonstrate that the Beauty is based on the intellection of unity, and that the ascension to the One is both aesthetic and intellectual.

KEYWORDS: Aesthetic. Soul. Mystical experience. Ascension. Plotinus.

No tratado I, 6 de Plotino, Sobre o Belo, o autor retoma importantes noções platônicas tais como encontradas, por exemplo, no Banquete e na República, elaborando, a seu modo, um tratado sobre o Belo ${ }^{1}$ que o coloca em estreita relação com a ética, a epistemologia e a metafísica platônica em geral, especialmente com o princípio do $\mathrm{Um}^{2}$ - a hipóstase

\footnotetext{
*Doutorado em Filosofia. Universidade Federal do Paraná. E-mail: leonnardi@ bol.com.br.

1 Optamos por manter "Belo", sempre em letra maiúscula, ao invés de especificar um "belo", com letra minúscula, atribuído a casos particulares que não dizem respeito ao Belo em geral. Um dos motivos para isso é que, em Plotino, os sentidos geral e específico se interseccionam e, além disso, o Belo não é uma hipóstase, tal como o Intelecto ou a Alma, para os quais os sentidos geral e específico podem ser mais bem diferenciados. Quando se tratar de um "belo" notadamente particular, falaremos em "beleza". No entanto, nas citações usadas, encontramos "belo" e "bem", mesmo quando em sentido geral, o que obviamente mantemos por respeito à escolha dos tradutores.

${ }^{2}$ Escolhemos aqui nomeá-lo como "Um", e não "Uno", já que "Uno" pode conduzir semanticamente à compreensão de que se trata de algo que possui substância passível de receber a qualificação de "una". Não se trata disso, porque o Um não é um ente. Para tentar evitar esse mal entendido, consideramos que "Um" seja mais apropriado.
} 
fundamental na filosofia de Plotino, de onde procedem não só a Alma e o Intelecto em geral ${ }^{3}$, mas também cada ente em particular ${ }^{4}$.

É bem conhecido, em Plotino, o itinerário de união com o Um que a alma empreende após a união consigo mesma, com a Alma do mundo e com o Intelecto ${ }^{5}$. No tratado Sobre o Belo, chega-se à união com o Um através do Belo. apresentado em diferentes termos, havendo estreita afinidade entre as vias estética ${ }^{6}$ e intelectiva.

Neste artigo, pretendemos mostrar que as vias estética e intelectiva não são disjuntas, mas coincidentes. Para isso, propomos que o Belo do tratado I, 6 seja entendido pelo que chamamos aqui de esplendor do Um: aquilo que, de certo modo, procede do Um, não sendo, no entanto, um ente, tampouco alguma das hipóstases plotinianas (a Alma, o Intelecto e o próprio Um), dando-se sempre que haja percepção da unidade, desejo de ascensão pela virtude e pela intelecção unificadoras da alma, sendo também um propulsor dessa caminhada do filósofo ${ }^{7}$. Não é só que ele se manifeste em tudo que participa do Um, mas seria ele próprio um caminho para o Um. Assim, o Belo deve desempenhar importante papel na filosofia de Plotino, sendo mais do que um mero vocábulo a definir o que seja bom ou afim à vida intelectiva do filósofo ${ }^{8}$, tratando-se não apenas de um conceito, mas de uma realidade.

Pretendemos fundamentar essa leitura do tratado I, 6 a partir de dois pontos: i) o Bem em I, 6 entendido no mesmo sentido do Um, sobretudo a partir do tratado VI, 9 (Sobre o Bem ou $o(U m)^{9}$; ii) o Belo enquanto via de intelecção e participação do Um.

Antes disso, porém, cabem algumas observações sobre I, 3 (o tratado Sobre a Dialética). É que ali Plotino afirma que o filósofo, o músico e o amante devem elevar-se em direção ao Bem (I, 3, 1, 10-11). A primeira distinção que se segue é entre os que devem partir das coisas de baixo e os que devem perscrutar todo o domínio inteligível, uma vez estando já lá (I, 3, 1, 13-18). E, antes de listar, respectivamente, as descrições do músico, do amante e do filósofo, Plotino nos informa que tratará primeiro da ascensão ${ }^{10}$. Pode-se supor que este seja o

\footnotetext{
${ }^{3}$ Ver tratados III 8; V 1; VI 7; VI 9.

${ }^{4}$ Ver VI 9, 1.

${ }^{5}$ Ver III 8, V 1, VI 9.

${ }^{6}$ Não se entenda aqui o termo "estética" em seu sentido estritamente etimológico (de $\left.\alpha i \sigma \theta \eta \sigma ı\right)$ ), ligado à percepção sensível. Falamos em "estético" aqui de modo muito mais geral: aquilo que diz respeito ao Belo.

${ }^{7} \mathrm{O}$ esplendor aqui dito não é um termo técnico de Plotino. No presente texto, escolhemos tal definição para o Belo de acordo com a leitura de I, 6 proposta.

${ }^{8}$ Isso embora, evidentemente, o termo $\kappa \alpha \lambda$ ó (ou $\tau$ ò $\kappa \alpha \lambda o ́ v$ ) seja comumente usado por Plotino em diferentes contextos, em sentidos ora mais amplos, ora mais específicos, como, aliás, costuma ocorrer também para outros

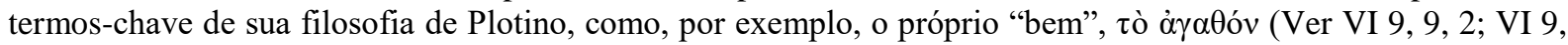
$9,22)$.

${ }^{9}$ De fato, a rigor, é preciso mostrar que o Bem tem em I, 6 o mesmo sentido do Bem de VI 9.

${ }^{10} \dot{\alpha} v \alpha \gamma \omega \gamma \eta \dot{ }$
} 
caso dos que se seguem imediatamente no texto (músico e amante), estando o filósofo já no inteligível, pronto e alado ${ }^{11}$. Isso poderia nos dizer que as vias estética (do amante) e intelectiva (do filósofo) seriam alternativas. Mas uma leitura mais atenta de I, 3 pode nos fazer notar que: na abertura do tratado, o filósofo também é listado dentre aqueles que devem experimentar a ascensão (I, 3, 1, 7-11); o músico pode se tornar um amante e, enquanto tal, ir ainda além (I, 3, 2, 1-2); o amante, uma vez tendo alcançado o intelecto, deve seguir seu caminho para o alto (I, 3, 2, 13-15). Ou seja, pode ser que músico, amante e filósofo descrevam estados de uma mesma via de ascensão em direção ao Um, o que pretendemos aqui corroborar a partir do exame do tratado Sobre o Belo.

O método investigativo de Plotino em I, 6, assim como em outros tratados, incorpora a dialética platônica. Partindo de opiniões comuns acerca do belo, bem como testando hipóteses propostas, ele busca entender o que seja o Belo em si. Uma atitude metodológica importante é a assunção de que o belo se dá na realidade como evidência. Ou seja, mesmo antes de poder defini-lo, é assumida como evidente a manifestação do Belo em muitas experiências humanas. Assim, Plotino abre seu tratado afirmando:

O belo está sobretudo na visão, mas está também na audição, por conta de combinações de palavras, e está também na música de todos os tipos: pois melodias e ritmos também são belos; há também, para aqueles que se elevam das sensações ao que é superior, belas ocupações, ações, hábitos, conhecimentos e ainda a beleza das virtudes. E se houver alguma ainda anterior a essas, ela mesma se mostrará. (I, 6, 1, $1-6)$.

Esse reconhecimento do Belo como um dado da realidade revela também um itinerário de ascensão, semelhante àquele do Banquete de Platão, que é explorado no tratado I, $6^{12}$. Nos capítulos 1 a 3 Plotino trata da beleza dos corpos. Nos capítulos 4 a 6, das coisas incorpóreas (ocupações, virtudes etc.). Nos capítulos 7 a 9, conclusivos, o tema é a beleza da alma e sua participação na contemplação do Bem ${ }^{13}$.

\footnotetext{
${ }^{11}$ Ver I, 3, 3, 1 - 4; Fedro $246 \mathrm{c} 1$.

${ }^{12}$ É digno de nota que tais afirmações sobre onde se encontra o belo não sejam de natureza hipotética e constem logo no início do tratado. Revela uma postura do filósofo segundo a qual já se admite em relação ao que está sendo investigando certa compreensão prévia que, embora ainda rudimentar, se apresenta segura.

${ }^{13}$ As linhas gerais dessa caminhada detalhada em I, 6 parecem constar em I, 3 de forma sintética: a harmonia dos sons, no mundo dos sentidos, afim à percepção do músico (I, 3, 1); a beleza das ocupações, ciências e virtudes, afim à apreensão do amante (I, 3, 2); a beleza anterior a essas para a qual o filósofo está pronto (I, 3, 3).
} 


\title{
1 O BEM (I, 6) E O UM (VI 9)
}

A descrição da atividade contemplativa do Bem, tal como apresentada em I, 6, capítulos 7 a 9, se coaduna com aquela de VI 9, como mostraremos a seguir. A novidade não reside em tratar o Um enquanto Bem ${ }^{14}$ (o sumo Bem). A questão é que o caminho para o Um se dê via Belo. Quer dizer, se a união com o Bem descrita em I, 6 é a mesma experiência mística do Um de VI, 9, então não só o Belo se manifesta à medida que se empreenda a jornada de ascensão: é ele próprio também o caminho para a união com o Um, sendo a união com o Bem em I, 6 o resultado de uma ascensão tanto estética quanto intelectiva através da experiência do Belo. Nesse sentido, na conclusão do tratado I, 6 é dito:

\begin{abstract}
Portanto, que primeiro se torne todo deiforme e todo belo, se alguém pretende contemplar deus e o belo. Pois, ao elevar-se chegará primeiro ao intelecto e, lá, saberá que são belas todas as formas e afirmará que a beleza é isto, as ideias: tudo é belo por causa delas, as filhas do intelecto e da essência. Mas ao que está além disso chamamos a natureza do bem, que tem o belo anteposto diante de si. Assim, em um discurso impreciso, ele é a beleza primária; mas se se distingue os inteligíveis, se dirá que a beleza inteligível é a região das formas, ao passo que o bem é o que está além, fonte e princípio do belo. Caso contrário, o bem e o belo seriam identificados; de qualquer modo, o belo está lá. (I, 6, 9, 32-44). ${ }^{15}$
\end{abstract}

Vê-se o quanto o Belo pode se confundir ora com o Intelecto, ora com o próprio Bem. O esforço de Plotino apresentado no texto demonstra, por um lado, uma tentativa de dar ao leitor a visão mais clara possível do que ele entende por Belo e, por outro, uma precaução em não lhe dar uma definição restrita e estanque, ressaltando tanto seus diferentes níveis de

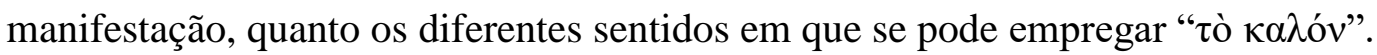

Assim o Belo aparece como manifestação de algo que emana do Um, e que também se lhe "antepõe". É como se o Belo orbitasse em torno do Bem, sobrepondo-o, sendo também dali surgido, já que o Bem é "fonte e princípio" do Belo. Também inspira e participa da própria constituição ontológica tanto do Intelecto quanto das coisas visíveis pois tudo depende do Um.

Vejamos agora mais especificamente a convergência entre o Bem de I, 6 e o Um de VI, 9. Neste último tratado, o estado amoroso da alma na contemplação do Um é descrito:

\footnotetext{
${ }^{14}$ Ver VI, 7, 36; VI, 9, 6, 29-30. É preciso, de qualquer forma, garantir que o Bem de I, 6 não conterá nenhuma nuance que o distinga do Bem/Um de outros tratados.

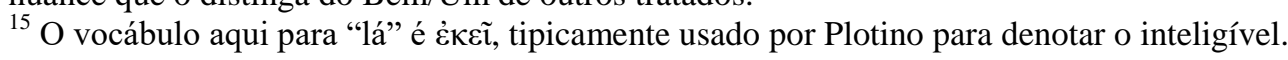


Mas se alguém não se dirige para a contemplação, nem sua alma tomou consciência do esplendor que existe lá, nem experimentou nem teve em si mesmo algo como uma afecção amorosa por ver (como o amante que repousa em quem ama), recebendo a luz verdadeira e iluminando toda a alma por estar mais perto; se ainda estando pesado por trás para subir, o que é um empecilho à contemplação, e se não sobe só, mas com aquilo que o separa dele, não ainda tendo reunido em um [...] se então ainda não está lá, mas, por causa disso, está fora, ou então pela insuficiência de um discurso pedagógico que lhe fornece confiança a respeito dele; se por causa dessas coisas, que seja acusado e que tente, afastando-se de tudo, ser só. (VI, 9, 4, 17-35).

Essa ultrapassagem das coisas que impedem a união amorosa também é descrita em I, 6, referindo-se ao Bem:

É preciso, então, ascender novamente ao bem, ao qual toda alma almeja. Se alguém o viu, sabe o que digo, como ele é belo. Ele é desejável por ser bom e o desejo tende a ele, mas a obtenção do bem é para aqueles que se alçam ao superior, que estão convertidos e que se despem do que vestimos ao decair [...] até que, ultrapassado na ascensão tudo quanto é alheio a deus, um o veja, solitário ao solitário imaculado, simples, puro, de quem todas as coisas dependem e para quem olham, por quem existem e vivem e inteligem: pois ele é causa da vida, do intelecto e do ser. Se, pois, alguém o visse, que amores sentiria! E que desejos, querendo confundir-se com ele! E como tremeria prazerosamente! (I, 6, 7, 1-14).

Ora, a causa do intelecto e do ser é a hipóstase $\mathrm{Um}^{16}$. Ressalte-se também, em ambas as descrições, a condição de solidão, seja da própria alma que se unifica com o Um, seja do próprio Bem. Além disso, certos discursos sobre o Um em VI 9 coincidem, em detalhes, com aqueles dedicados ao Bem em I, 6. Vejamos dois trechos que exemplificam isso, começando com o tratado Sobre o Belo, onde encontramos a seguinte descrição do encontro com o Bem:

Se te tornaste isso, e viste isso, e se puro te consocias contigo sem ter impedimento algum a esse tipo de unificação e sem ter em teu interior algo alheio mesclado a ti, mas sendo tu inteiro luz verdadeira apenas, não medida por dimensão, não confinada à pequenez por um contorno, nem dilatada em dimensão através da ilimitabilidade, mas imensurável totalmente, como maior que todo metro e mais que toda quantidade: se vês que tu te tornaste isso, já tornado visão, confiando em ti e já aqui acimalçado, sem mais careceres de guia, fixa o olhar e vê: pois esse é o único olho que vê a súpera beleza. (I, 6, 9, 15-24).

A condição de uma imensurabilidade total, que não se deve a uma grandeza infinita, mas à própria ausência de grandeza, Plotino também usa para falar do Um em VI, 9:

Como então dizemos Um e com o isso deve ser adaptado à intelecção? Supondo-o ser mais um do que a mônada e o ponto são unificados. Pois, no caso deles, abstraindo a grandeza e a multiplicidade do número, e alma termina no que é menor

${ }^{16}$ Ver III, 8, 9-10; V, 1, 5; VI, 9, 2.

Sapere aude - Belo Horizonte, v. 10 - n. 19, p. 61-72, Jan./Jun. 2019 - ISSN: 2177-6342 
e se apoia em algo certamente indivisível, mas que existia no divisível e que existe em outro. Contudo, o Um não existe nem em outro, nem no divisível, nem é sem partes como a menor coisa. É a maior de todas as coisas, não pela grandeza, mas pela potência, de modo que também é sem grandeza na potência. Pois também os entes que vêm depois dele são indivisíveis e sem partes nas suas potências, não em seu volume. (VI 9, 6, 1-10).

Trata-se aqui de uma abordagem típica de um discurso apofático ${ }^{17}$ : afinal, o Um (Bem) não pode ser propriamente falado, a não ser por analogia. É clara a concordância entre as descrições do que se alcança através da jornada do Belo (o Bem de I, 6) e do que se obtém pela ascensão através da Alma e do Intelecto (o Um de VI, 9).

\section{O BELO ENQUANTO VIA DE INTELECÇÃO E PARTICIPAÇÃO DO UM}

Tendo sido mostrado que o ponto de chegada da via estética coincide com aquele da via intelectiva ${ }^{18}$, é preciso mostrar também que o próprio caminho do Belo coincide com o do Intelecto. Para isso, pretendemos mostrar em I, 6 que os diferentes níveis do Belo se dão em termos de diferentes graus de participação do Um. Isto é: algo é tão belo quanto mais possui unidade. Não que a unidade seja a beleza: é que a beleza emerge imediatamente da unidade. Como a unidade tende a ser mais plena tanto mais a alma se aproxima de sua união com o Intelecto, e mais ainda quando vai além deste ${ }^{19}$, assim também o Belo se manifesta em toda sua plenitude à medida que a alma se aproxima do Um. Além disso, o Belo atrai a alma para essa união, ou seja, para que seja ela mesma. Resulta daí que, em um círculo virtuoso, o Belo é fruto e também propiciador da vida contemplativa. É o que pretendemos mostrar a seguir, seguindo itinerário da investigação acerca do Belo em I, 6.

Nos capítulos 1 a 3 do tratado, Plotino concentra sua investigação na beleza dos corpos. Começando com as coisas sensíveis, ao indagar-se sobre o que fundamenta a beleza nos corpos, Plotino valia a tese estoica da beleza enquanto resultado da simetria (I, 6, 1, 1754). Ele a rejeita, porém, baseado em três objeções: i) a simetria só pode ser construída a partir de partes simples, e por isso seria preciso dizer que partes simples seriam belas. Mas

\footnotetext{
${ }^{17}$ Um discurso de negação: só se pode falar com segurança a respeito do Um o que ele não é, por isso o discurso é de negação. Discursos afirmativos a respeito dele só podem ser entendidos em sentido analógico, com um fim anagógico.

${ }^{18} \mathrm{O}$ estado de intelecção é, notadamente, uma marca da alma unida do Um. Ver VI, 9, 9, 1-5 e VI, 9, 9, 15: “[...] observa a fonte de vida, a fonte do Intelecto, o princípio do ente, a causa do bem, a raiz da alma [...] E ali intelige e é impassível. A vida verdadeira é ali. Pois a de agora, fora do deus, é um vestígio de vida que imita aquela, mas ali, o viver é a atividade do Intelecto".

${ }^{19}$ Não se entenda aqui "além" como um outro mundo ou nível exterior a uma realidade inferior. Na verdade, podemos entender o Intelecto e o Um de Plotino como níveis de uma mesma e única realidade das coisas (ver VI, 9, 7, 1-6; VI, 9, 1, 1-15; VI, 9, 2, 16-29; VI 9, 2, 45-47).
} 
não seria possível afirmá-lo, já que esses elementos não podem ser simétricos, por não possuírem partes. Também ficariam excluídas da beleza, por exemplo, as belas cores e o ouro, já que são simples; ii) há simetrias não belas, como a de certos semblantes e certas afirmações (como a simetria encontrada no seguinte par e afirmações: "a justiça é uma ingenuidade" e "a temperança é uma idiotice”); iii) há certas ocupações, leis e ciências para as quais nem faz sentido avaliar simetria, sendo porém belas.

O que seria então a beleza nos corpos? É na unidade da forma (cĩ $\delta o \varsigma)$ que Plotino apoia sua resposta, pois:

[...] a forma, advindo, compõe e coordena aquilo que vai ser algo uno e composto de muitas partes, e o conduz a uma completude una e nele produz a unidade através da concordância, pois, sendo ela una, o que foi por ela enformado também deveria ser uno, na medida de suas possibilidades, uma vez que é composto de múltiplas partes. Assim, a beleza se assenta sobre ele, quando ele já está reduzido à unidade, doando-se às partes e ao todo. Quando ela toma algo uno e isômero, dá ao todo a mesma beleza: assim como, em certas ocasiões, a arte dá beleza a toda uma casa com suas partes e, noutras, uma natureza o faz a uma única pedra. Assim, pois, o corpo belo surge da comunhão com uma razão provinda dos seres divinos (I, $6,2,18-29$, grifos nossos).

A beleza dos corpos, portanto, procede da unidade da forma. Esta, por sua vez, reside na alma, e, portanto, há um processo de juízo que a alma precisa fazer olhando também para si mesma enquanto reconhece o belo ${ }^{20}$. Isso fica ainda mais patente quando da percepção do belo naquilo que não cabe à sensação ver: as belas ocupações, belos modos e as virtudes (capítulos 4 a 6). Com efeito,

\begin{abstract}
Vós, vendo-vos belos em vossos interiores, que experimentais? Como vos dionisais, e vos excitais, e desejais congregar-vos convosco, colhendo-vos de vossos corpos? Pois é isso que sentem os verdadeiros amantes! Que é isso, arredor ao qual eles experimentam essas afecções? Não é uma figura, nem uma cor, nem uma grandeza, mas algo na alma, ela que é incolor, e incolor é a temperança que ela possui, bem como qualquer outro brilho das virtudes, sempre que vides em vós ou vislumbrais em outrem a grandeza da alma, o comportamento justo, a temperança imaculada, a coragem detentora de face austera, a dignidade, o pudor que se difunde com disposição firme, tranquila e impassível, e o intelecto deiforme sobreluzindo sobre tudo isso. Então, venerando e amando essas coisas, como as denominamos belas? Elas existem e se manifestam, e quem as viu jamais diria que elas são algo outro senão o que realmente existe. (I, 6, 2, 18-29).
\end{abstract}

Esse encontro da alma consigo mesma, com sua natureza intelectual divina, é o seu abrir dos olhos para que possa ver o que não é sensível. Tal como o reconhecimento da forma

\footnotetext{
${ }^{20}$ Ver I, 6, 3, 1-5.
} 
dentro de si era condição para sua identificação nos corpos, assim também ver-se belo no interior é condição para reconhecer a virtude em outrem:

Como verias o tipo de beleza que uma alma boa possui? Recolhe-te em ti mesmo e vê; e se ainda não te vires belo, como o escultor de uma estátua que deve tornar-se bela apara isso e corrige aquilo [...] até que resplandeça em ti o esplendor deiforme da virtude. (I, 6, 9,6-13).

De fato, há para a alma o equivalente à cegueira do corpo para o mundo sensível ${ }^{21}$. Uma alma cega para as coisas superiores é aquela impura, voltada por sua atração desmedida ao sensível, o que a torna suja, não revelando a beleza que possui, já que permite se lhe adicionar o que é alheio (I, 6, 5, 38-58).

Mas como, exatamente, a desatenção às coisas superiores da alma a torna feia? Não pode ser pela feiura das coisas visíveis, já que, na verdade, as coisas sensíveis também são belas enquanto têm a matéria unificada pela forma. Na verdade, os corpos são o ponto de partida para a jornada do Belo, já que sua beleza é imagem do inteligível (I, 6, 5, 38-58). Trata-se, antes, de um desajuste da busca da alma, retida em demasia pelos corpos ${ }^{22}$. Poderíamos dizer: a alma se torna feia quando se esquece de que a beleza dos corpos é um meio de ascensão à beleza que lhe é anterior, não um fim em si mesmo. Assim,

\begin{abstract}
Seja uma alma feia, licenciosa e injusta, infestada de muitíssimas concupiscências, de muitíssimas perturbações, em terror por sua covardia, em inveja por sua ignobilidade, tudo em que pensa (se é que pensa) é perecível e abjeto, completamente corrompida, amiga de prazeres não puros [...] Não diremos nós que essa mesma fealdade lhe foi aditada como um mal adventício, que não só a danificou, mas também a tornou impura e misturada a muito de mal, sem mais possuir vida nem percepção puras, mas que, vivendo uma vida frágil devido à mescla com o mal e estando por demais fundida à morte, sem mais ver o que uma alma deve ver e sem mais se permitir permanecer em si mesma por ser sempre arrastada para o exterior e para o inferior e para o obscuro? (I, 6, 5, 38-58, grifo nosso).
\end{abstract}

Desse modo, a entrega à fealdade implica uma não permanência em si mesma, uma desatenção de si, voltando-se para fora. Plotino também afirma que a beleza da alma se manifesta quando ela permanece sozinha consigo mesma $\left(\mu \varepsilon^{\prime} v \alpha \sigma \alpha \mu \text { óvๆ }\right)^{23}$. A beleza da alma

\footnotetext{
${ }^{21}$ Ver I, 6, 4, 1-15.

${ }^{22}$ A esse respeito, é digno de nota que, a fim de contemplar o Um, é preciso que a alma se despoje também das formas inteligíveis e até de si mesma (Ver VI, 9, 7, 18-21). Assim, a questão não é apenas a materialidade dos corpos (embora, sim, a matéria amorfa seja má), mas o apego desajustado a qualquer coisa que afaste a alma da finalidade suprema da vida filosófica.

${ }^{23}$ Ver I, 6, 5, 50-58.
} 
advém de uma unificação por permanecer na simplicidade. Mais uma vez, é da participação da unidade que procede o belo.

E se o Intelecto, embora tenha de certo modo ousado se separar do Um, tem privilégio de unidade em relação à Alma, já que intelige a si mesmo, não se dispersando e permanecendo sempre consigo próprio ${ }^{24}$, é de se esperar que uma beleza baseada na unidade passe por uma união da alma com o Intelecto. Aliás, mesmo a beleza dos corpos decorre da unificação dada pelas formas, e estas habitam no Intelecto. De fato, no capítulo 6 do tratado Sobre o Belo, assim Plotino nos descreve o Belo na alma em união com o Intelecto:

\begin{abstract}
A alma, estando purificada, torna-se então forma e razão, inteiramente incorpórea, intelectual e toda ela pertencente ao divino, donde provém a fonte do belo e todas as coisas congêneres desse tipo. A alma assim alçada ao intelecto torna-se cada vez mais bela. $\mathrm{O}$ intelecto e as coisas dele oriundas são a beleza própria e não alheia da alma, pois nesse momento ela é verdadeiramente apenas alma. (I, 6, 6, 12-18, grifos nossos).
\end{abstract}

Ele também afirma: “[...] deve-se estabelecer a beldade, que também é o bem: dele provém imediatamente o intelecto enquanto o belo; a alma é bela pelo intelecto: e as demais são belas devido à alma que as enforma" (I, 6, 6, 25-28). Assim, a alma é bela quando unida ao Intelecto porque ali nada lhe é alheio, e é onde ela está mais próxima do Um antes de sua suprema unificação, e onde já é apenas ela própria. E isso é importante: não é que a caminhada da ascensão seja um tipo de levitação que leva a alma a outro lugar, mas, sim, é uma jornada de encontro da alma consigo mesma, de reunificação. E neste ponto podemos dizer que o amante se torna filósofo (I, 3, 2-3).

Vê-se então a beleza procedendo da unidade encontrada em cada etapa da ascensão estética. Começando pelos corpos, unificados pelas formas, que são unas e unificantes, passando pelas virtudes, que fazem a alma residir em si mesma em simplicidade, chegando ao Intelecto, tão uno (embora não seja ainda o Um) que pode se confundir com o próprio Belo. $\mathrm{O}$ Belo, em seus diferentes graus, se manifesta como esplendor do Bem: onde este está, ali o Belo aparece, não como um ente causado, mas como manifestação da presença da unidade do Bem, como um esplendor do Um.

Quanto à relação da beleza com o inteligível, é importante notar que ela diz respeito tanto ao inteligível em sua constituição e forma de atualização, quanto a sua fonte de bondade. A partir do tratado VI, 7, a luz inteligível descrita por Plotino é condição para a existência e

\footnotetext{
${ }^{24}$ Ver VI, 9, 5, 25-30.
} 
visibilidade do próprio intelecto, sendo provinda do Um e fornecendo aquela beleza que confere o caráter desejável aos inteligíveis e torna o Intelecto bom. Essa luz que nele se

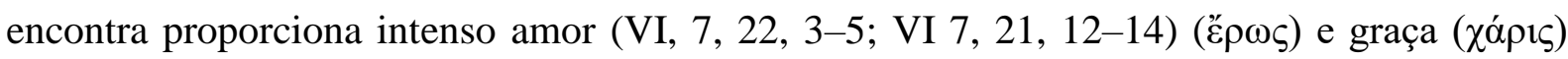
(VI, 7, 22, 6-8), não se confundindo, porém, com o próprio intelecto naquilo que ele é, embora lhe seja coextensiva, mas sendo advinda do que lhe é anterior (do Bem). É dessa maneira que o Um inspira os inteligentes a inteligir, e os viventes a viver, assim como o próprio existir (VI, 7, 23, 22-25).

Assim, as coisas inteligíveis se tornam belas pela luz que recebem do que lhe é anterior, do Bem, sendo a beleza do inteligível, em si, amorfa, de acordo com sua origem, tomando forma somente enquanto se encontra no inteligível determinado que a manifesta (VI, $7,34,34-40)$.

Enfim, o sumo Belo se dá na união com o sumo Bem:

Se alguém o viu [o bem], sabe o que digo, como ele é belo. Ele é desejável por ser bom e o desejo tende a ele, mas a obtenção do bem é para aqueles que se alçam ao superior, que estão convertidos e que se despem do que vestimos ao decair - assim como para aqueles que se alteiam aos ritos sagrados dos templos há purificações, despojamentos das vestes de antes e o avançarem nus -, até que, ultrapassado na ascensão todo quanto é alheio a deus, um o veja, solitário ao solitário imaculado, simples, puro, de quem todas as coisas dependem e para quem olham, por quem existem e vivem e inteligem: pois ele é a causa da vida, do intelecto e do ser. (I, 6, 7, $1-12)$.

Note-se aí a procedência originária do Belo (que não é o mesmo que o Bem, eles não estão identificados, mas o Bem tem o Belo anteposto diante de si (I, 6, 9, 32-44), não como uma quarta hipóstase, mas como um tipo de esplendor). Além disso, o Belo é caminho para a união com o Um. Com efeito, "o desejo tende" ao Bem, o que significa que tal desejo impulsiona o filósofo em busca do Um, ultrapassando na ascensão tudo que outrora havia usado como meio de participação secundária da unidade.

O Bem torna o filósofo um amante e o faz tremer de prazer (I, 6, 7, 12-14). Como a ascensão, como descrita no tratado I, 6 é estética, segue-se que o Belo é tanto o caminho quanto aquilo que conduz o filósofo ao Um, porque o atrai como um amado. Com efeito, o Belo encontrado no sumo Bem é de tal ordem que:

[...] sendo ela mesma a beleza suprema e a primária, lavra belos amantes e os torna amáveis. E eis que se põe o combate maior e extremo para as almas, e todo nosso labor é para isso, para não ficarmos sem parte no mais sublime espetáculo: abençoado quem o alcançou, tendo contemplado abençoada visão, e desgraçado quem não o alcançou. (I, 6, 7, 31-35). 
Portanto, irradiando a partir do Bem, o Belo faz amantes enquanto os torna belos (amáveis). Faz então com que o filósofo deseje o Um, enquanto o torna cada vez mais Um. É a meta buscada na jornada, e também o alimento daquele que a empreende. No sumo Bem reside a mais sublime união, que também é o mais sublime espetáculo do Belo.

\section{CONSIDERAÇÕES FINAIS}

A partir do que foi exposto, consideramos que há um lugar muito importante para o Belo na filosofia de Plotino. Ou seja, não se trataria de atribuir "belo" apenas como um adjetivo que acompanha as diferentes experiências da alma em uma ascensão que seria em um primeiro momento intelectiva e, em um segundo, mística. Isto é verdade: a ascensão preconizada por Plotino exige uma união com o Intelecto, antes que se dê a união com o Um, quando o filosofo se despoja até mesmo de sua bagagem intelectiva ${ }^{25}$. Mas poderíamos qualificar essa jornada também de outro modo: ela é também estética ${ }^{26}$, através do Belo que emerge em cada nível da experiência com o Um. Em certo sentido, trata-se de um aspecto dionisíaco da intelecção. É como se o Amor fosse o guia do Intelecto: sem o desejo pelo que o seduz, a atividade intelectiva não saberia para onde apontar seu olhar. A sedução da beleza e o desejo erótico do Bem, tanto quanto a constante intelecção, são fundamentais para a ascensão filosófica.

Apesar de indicações passageiras desse aspecto estético da ascensão em outros tratados, é em Sobre o Belo que ele se desenvolve. A partir disso, podemos supor que a distinção entre músico, amante e filósofo de I, 3 não seja referente necessariamente a vias paralelas de acesso ao Um. Denotariam, assim, etapas de um mesmo itinerário de ascensão. Embora não seja esse o escopo do presente artigo, a partir do que aqui se considerou entendemos que seja uma hipótese válida a ser examinada em mais detalhes em outros tratados.

Seja como for, em I, 6 o Belo é apresentado como aquilo que determina a jornada de ascensão, no sentido de que ele a preenche desde o início (os corpos visíveis) até o fim (o sumo Bem). E como não se trata de uma hipóstase, mas de uma manifestação da presença do Um, escolhemos assim por denominá-lo esplendor do Um.

\footnotetext{
${ }^{25}$ Como um iniciado que, após conviver com as estátuas do templo, soube penetrar em seu interior (ver VI, 9, $11,16-26$.$) .$

26 “estética" em sentido geral, não só ligado à percepção sensível (I, 3,1, 13-18).
} 


\section{REFERÊNCIAS}

PLOTINUS. Ennead IV. Translation: A. H. Armstrong. Cambridge, MA: Harvard University Press, 2004.

PLOTINUS. Ennead V. Translation: A. H. Armstrong. Cambridge, MA: Harvard University Press, 1984.

PLOTINUS. Ennead VI, 1-5. Translation: A. H. Armstrong. Cambridge, MA: Harvard University Press, 2006.

PLOTINUS. Ennead VI, 6-9. Translation: A. H. Cambridge, MA: Harvard University Press, 1988.

PLOTINUS. Porphyry on the Life of Plotinus. Ennead I. Translation: A. H. Cambridge, MA: Harvard University Press, 1989. 